MATEC Web of Conferences 13, 02003

(2014)

DOI: $10.1051 /$ matecconf/ 20141302003

(C) Owned by the authors, published by EDP Sciences, 2014

\title{
Installation Capacity Assessment of Damaged Deepwater Pipelines
}

\author{
R. Ramasamy ${ }^{1, a}$, T.M.Y.S. Tuan $\mathrm{Ya}^{2}$ \\ ${ }^{1}$ Faculty of Engineering, University of Malaya, 50603 Kuala Lumpur, Malaysia. \\ ${ }^{2}$ Faculty of Engineering, Universiti Teknologi PETRONAS, 31750 Tronoh, Perak, Malaysia.
}

\begin{abstract}
The worldwide exploration and development of subsea and deepwater reservoirs has laid down some new and old engineering challenges to the offshore pipeline industry. This requires large $\mathrm{D} / \mathrm{t}$ pipelines to be installed at water depths in the vicinity of up to $2700 \mathrm{~m}$. The deepwater collapse and buckle propagation event is almost unavoidable as the pipe wall thickness cannot be always determined from the codes and standards due to the limit state criteria. These codes also do not consider any fabrication imperfections and sustained damages emanating from transportation and handling. The objective of this paper is to present the Finite Element Analysis (FEA) of dented pipes with $\mathrm{D} / \mathrm{t}$ ratio more than 45 , which is outside the applicability of current design codes, and to investigate the effects on installation capacity of these various damage sizes in terms of collapse and buckle propagation.
\end{abstract}

\section{Introduction}

Oil and gas developments have begun to explore from subsea into deeper water regions in Malaysia and other places in the world. What used to be the zone definition of deepwater 10 years ago, no longer applies now. For example, 200m water depth was defined as deepwater about 10 years ago, and today, in some regions, the depths of deepwater regime drops down to beyond $1000 \mathrm{~m}$ or even down to $2740 \mathrm{~m}$, like in the case of new oil reservoirs development in the Gulf of Mexico [1]. There are various limit states need to be considered in the design of steel pipelines wall thickness (WT) for deepwater applications such as containment pressure, global buckling, local collapse and propagations. In many cases, the selection of WT must be also economically feasible, in addition to be able to prevent buckle propagation. This is due to fact that collapse pressure is much higher than propagation pressure and the devastating cost impact on pipelines that are subjected to buckle propagation if it is left uninhibited. Physical measurement and observations from the field have shown that once collapse occurs, many kilometres of pipeline can propagate this collapse instantly. Evaluation of the propagation pressure is thus crucial to the understanding and control of collapse in the event of pipe, subjected to initial dents or damage prior to installation.

The choice of design criteria to evaluate the collapse and buckle propagation pressures must be correlated to experimental and any available field data, incorporating overall safety objective. This should consider the characteristics of pipe material (yield strength) and geometrical characteristics of the pipe (wall thickness, ovality). Based on these requirements, the DNV OS-F101 [2] is considered the most suitable design code for deepwater pipeline applications, mainly due to a concise correlation between complete sets of design loads, safety objective and addressed specifically for submarine pipelines using reliable methods resulting in acceptable failure probabilities. This unfortunately, is not sufficient to protect pipelines against collapse and buckle propagations. Due to the massive scale of

amfirdausb@ump.edu.my

This is an Open Access article distributed under the terms of the Creative Commons Attribution License 2.0, which permits unrestricted use, distribution, and reproduction in any medium, provided the original work is properly cited. 
these structures, the rigorous conditions during transportation, handling and installation under harsh environment, damages to the pipes in the form of dents often occurs. Dents can also occur from impact with other objects, trenching or a combination of these factors. These dents can result in loss of pipe capacity to withstand local collapse which will result in the initiation of buckle propagation. The integrity of these pipes must be evaluated once dents are detected, and due to complexity and cost factors involved, integrity assessment by reliable numerical means must be engaged.

A more engineer-oriented, robust and practical assessment method is required to assess damaged free-issued pipelines for safe operations in the deepwater region, and this can be found in the finite element methods available in commercial codes such as ABAQUS[3]. With current advent in computing power and its application to numerical methods, namely finite element (FE) methods, have opened up an opportunity for some further research into the determination of local collapse of pipes and the understanding of post-collapse behaviour of buckling propagation under external hydrostatic pressure present at great depths, and omit all unnecessary costs on abandonment and replacement of damaged pipes. This work will focus primarily on the employment of FE methods in ABAQUS to assess the integrity of dented pipelines pertaining to collapse and post-collapse propagation across the pipe span.

\section{Collapse and Buckle Propagation}

Pipeline with excessive bending and hydrostatic pressure may succumb to collapse, hence followed by the propagation of the buckle across the pipe span. Similar occurrence can also transpire on a geometrically imperfect pipe, or pipe with initial dent. The sequence of the pipe collapse, followed by the propagation of the buckle stages is shown in Figure 1. The first stage (a) shows the external pressure reaching a maximum value and the ovality of the pipe section forming, thus reducing the roundness of the outer diameter in (b). This is then followed by further localisation of this maximum pressure resulting in progressive instability finally collapse of the pipe section in (c). Further continued loading on the collapsed section will result in the buckle fully propagated across the span as shown in(d). In submarine pipelines, the prevailing instability leading to collapse is governed by its material plasticity, and this material non-linearity can complicate the collapse process and thereafter the propagation of the buckle across the pipe span. Pipeline with initial local damage or dent, presenting a local imperfection may fail at high hydrostatic pressure. The pressure required to collapse the pipe section is generally higher than the pressure required to further propagate the buckle along its $\operatorname{span}[4]$.

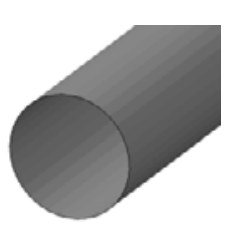

(a)

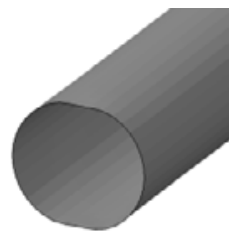

(b)

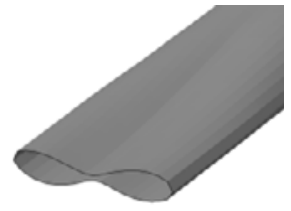

(d)

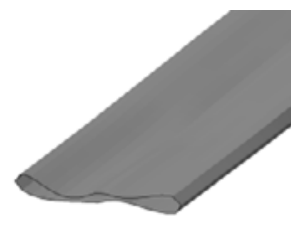

(c)

The most common practice when installing an offshore pipeline is to install them empty, i.e. to install them in the absence of the internal pressure. This is to reduce the tension required during installation, which is required to balance the suspended weight during pipelay. During maintenance of in-service pipes, the contents are emptied and the pipes de-pressurised on a periodic basis. This makes the external hydrostatic pressure a very important parameter to be considered during pipe design and pipelay operations. Usually the thinner pipes used in shallow waters buckle elastically, but collapsedue to inelastic action, and can be shown by deriving the collapse pressure required for an initial ovalized section. On the contrary, thicker pipes used in deepwater operations buckle and collapses in the plastic region and can be directly derived from plastic buckling equations [5], but, the presence of initial imperfections, damages, residual stresses and material plasticity on pipes may make it somewhat depend on numerical techniques to be employed to obtain a more realistic capacity. 


\section{Numerical Modelling}

The process of denting, collapse and propagating buckle is simulated using the commercial nonlinear code ABAQUS. In this case, a 20 m axisymmetric pipe span $(>15 \times \mathrm{D})$ of the 48 ' $(\mathrm{D} / \mathrm{t}=59)$ pipe was modelled and material nonlinearities were input to cater for hardening and residual stresses resulting from the damage. The pipe geometry and material data are shown below in Table 1 . The material elastic-plastic behaviour is in accordance specifications in Figure 2[6].

Table 1. Pipe Geometry (48in D) and Material (X65) data

\begin{tabular}{lcll}
\hline Parameter & Value & \multicolumn{1}{c}{ Parameter } & Value \\
\hline $\mathrm{D}(\mathrm{mm})$ & 1219.2 & $\mathrm{E}(\mathrm{MPa})$ & 210000 \\
$\mathrm{~T}(\mathrm{~mm})$ & 20.62 & $v$ & 0.33 \\
Grade & $\mathrm{X} 65$ & $\sigma_{\mathrm{o}}(\mathrm{MPa})$ & 448 \\
$\mathrm{f}_{0}$ & 0.67 & $\sigma_{\mathrm{UTS}}(\mathrm{MPa})$ & 535 \\
$\mathrm{~L}(\mathrm{~m})$ & 20 & $\rho(\mathrm{kg} / \mathrm{m} 3)$ & 7850 \\
\hline
\end{tabular}

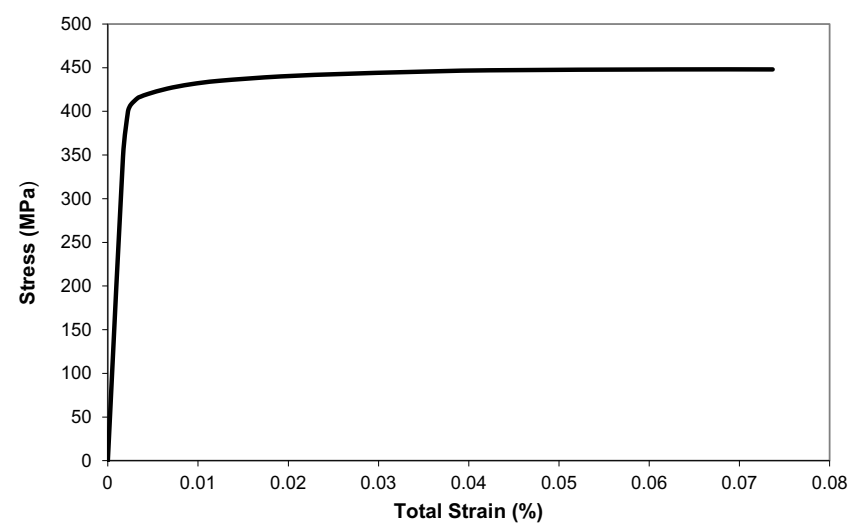

Figure 2. Stress-Strain Curve for X65 as per EP2005-5154 [6]

The axisymmetric pipe span was modelled using 4-noded S4R 3-D quadrilateral shell elements with reduced integration and finite strain kinematics. The internal cavity of the pipe was also meshed to cater for volumetric reduction during collapse and propagation using the fluid hydrostatic elements F3D4 with 4-noded and 3 degrees-of-freedom representing fluid-filled cavity with uniform temperature and pressure. The indenters were modelled using rigid elements and assigned an arbitrary friction coefficient of 0.3 to cater for any sliding or rotation of the elements in contact. An initial ovality of $0.67 \%$ was considered as fabrication tolerance.

\section{Results}

\subsection{Collapse}

The collapse analysis was carried out using the implicit dynamics step, following the preceding static indentation. The rigid indenter plates are carefully removed avoiding any elastic spring-back action of the section, leaving the dented pipe with the plastic residual stresses carried forward by the damage. The pipe thenundergoes small increments of external pressure representing various operational depths and the collapse of the pipe-end circumference is monitored by the minimum radial displacement which results in the pipe top and bottom circumferential points approaching each other at mid-plane, and the value is extracted for a force-displacement time-trace at maximum radial closure. The collapse incident of the $250 \mathrm{~mm}$ flat dent case is shown in Figure 3 below. 
(a)

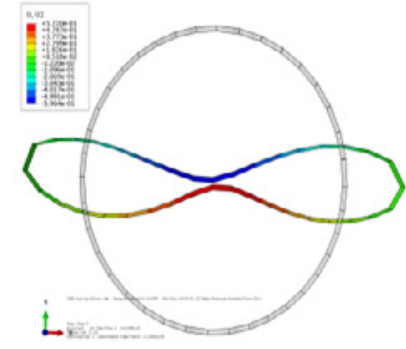

(b)

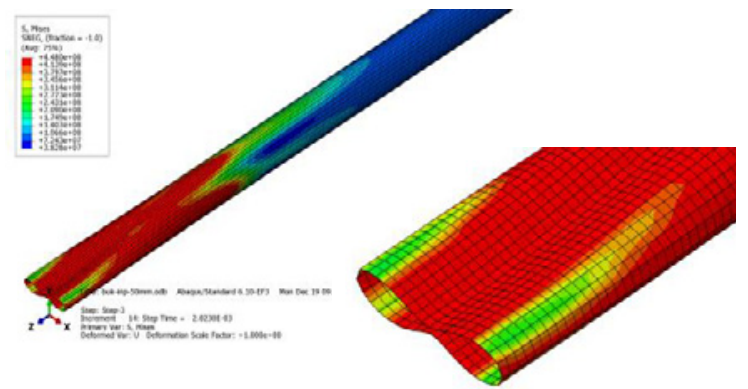

Figure 3. Collapse of Pipe for Flat Dent 250mm Case Showing (a) Minimum Radial Displacement Achieved, and (b) Stress Contour at Collapse.

\subsection{Buckle Propagation}

The propagation of the buckle is the event where the collapse on the pipe-end travelling across the span at great speed, rendering the pipeline segment useless for fluid transportation. This buckle propagation pressure $\left(\mathrm{P}_{\mathrm{P}}\right)$ occurs at a much lower pressure than $\mathrm{P}_{\mathrm{C}}$ and in most cases, and the $\mathrm{P}_{\mathrm{P}} / \mathrm{P}_{\mathrm{C}}$ ratios have been reported to be as low as 15 to $20 \%$ [7]. The volumetric reduction resulting from the occurrence of local buckle and subsequent propagation of this buckle is shown in Figure 4 for the flat dent of depth $250 \mathrm{~mm}$, where the converged volume plot indicating maximum flattening of the pipe $\mathrm{D}$, hence corresponding to propagation pressure.

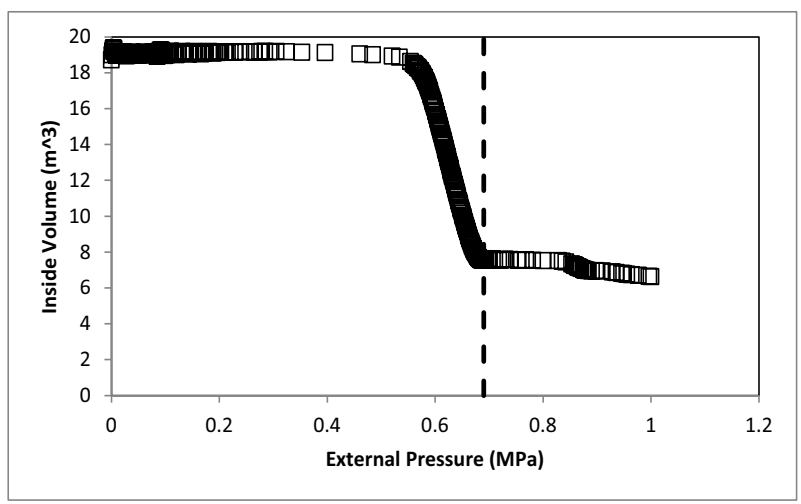

Figure 4 - Internal volume reduction during buckle propagation for Flat Dent Depth of $250 \mathrm{~mm}$

\section{Discussion and Conclusion}

The entire range of dents applied onto the pipe sections are shown in Figure 5 for, (a) the resulting $\mathrm{Pc} / \mathrm{Pp}$ ratios of various initial dents, and (b) comparison against theoretical expressions of similar scope. For a smaller dent size, this ratio approximately reaches the value of 3 , whilst saturating at unity for much larger dents indicating the severity of the damage, hence limiting the extent of damage sustainable on pipe sections prior to installation. Comparison of Pc is made against available theoretical expressions considering the ideal ring analogy from [5] and another theoretical expression considering initial ovality representing dents [11]. This shows the bounding theoretical expressions[5] on the results from FEA with the ring analogy simplification being the upper under-conservative bound, whilst the expression considering ovality being more conservatively derived. The formulation from ring analogy does not consider any material plasticity or initial dent on the cross section, hence producing an under-conservative solution for collapse of circular section. This, however, is not the 
case for the theoretical expression in [11] which considers the material plasticity and initial ovality of the circular section, resulting from indentation, hence forming the more conservative lower-bound.
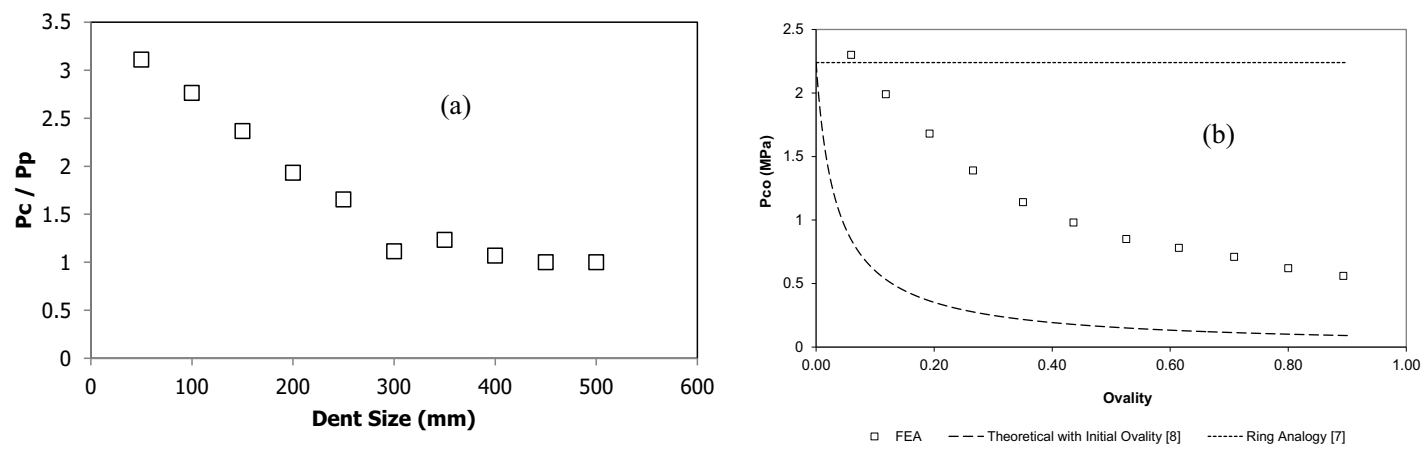

Figure 5 - (a) Normalised Pc/Pp for Indentation Range, and (b) Comparison with Theory

In this research, the main objective was to establish an acceptable practical methodology for the use of finite element methods as a robust engineering tool to compute the collapse and buckle propagation pressure of dented pipes with $\mathrm{D} / \mathrm{t}>45$ intended for submarine operations. This was deemed necessary for various reasons listed: design code limitation, ovality considerations instead of dents, intricate theoretical expressions, lack of experimental data and costing aspects of abandonment. Establishing the proper methodology to model line pipes with initial imperfections in the form of dents is a crucial process that should consider the various effects involved in the determination of local buckle of the pipe section at collapse pressure and the post-collapse propagation of this local buckle at the propagation pressure. The evaluation of collapse and propagation pressures for various initial imperfections are vital and have high impact on the ecological and economical aspects of facilities and pipeline installations.

Cost efficient solutions and decisions can be made with the knowledge of the pipe utilization factors obtained from the evaluation of collapse and buckle propagation pressures for specific dent shape and size as this work have elaborated and detailed out. Unnecessary abandonment of damaged pipes can be avoided and at the same time dangerously dented pipes can also be identified and taken out of the installation.

\section{References}

[1] J. Sun and P. Jukes, "Finite Element Analysis of Clamp-On Buckle Arrestor for Pipe-in-Pipe Flowlines by Reel-Lay installation", Proceedings of the ASME 27th International Conference on Offshore Mechanics and Arctic engineering, OMAE2008-57276, Estoril, Portugal, (2008).

[2] Offshore Standards DNV-OS-F101, Submarine Pipeline Systems, Det Norske Veritas, (2000).

[3] Abaqus Theory Manual version 6.10, (2010)

[4] T. D. Park and S. Kyriakides, On the Performance of Integral Buckle Arrestor for Offshore Pipelines, Int Journal Mechanical Sciences, Vol.39 No 6, pp. 643-669, (1997).

[5] G. H. Bryan, Application of the Energy Test to the Collapse of a Long Pipe Under External Pressure, Proc of Cambridge Phil Society, Vol. 6, 287-292 (1888).

[6] B.V, Rijswijk, Design specification for a Clad Pipeline subject to Lateral Buckling on a flat, Soft Clay Seabed, EP 2005-5154, Shell International Exploration and production, (2005).

[7] M. K. Yeh and S. Kyriakides, Collapse of Deepwater Pipelines, ASME J. Energy Resource Tehnol, 110, pp. 1-11, (1988)

[8] API Recommended Practices 1111, Design, Construction, Operations and Maintenance of Offshore Hydrocarbon Pipeline (Limit State Design) American Petro. Institute, 3rd Ed., (1999).

[9] C. R. Kennedy and J. T. Venard, Collapse of Tubes By External Pressure, Oak Ridge National Laboratory, A Report Submitted to US Atomic Energy Commission, ORN-TM-166, (1962).

[10] M. Levy, memoirs of an Integral case of the Problem of Elasticity and one of Its Application, J. Math Pure et Appl (Liouville), series 3, Vol 10, pp5-42 (1884) 
[11] S. Kyriakides and E. Corona, Mechanics of Offshore Pipeline, Volume 1: Buckling and Collapse, Elsevier (2007).

[12] S. P. Timoshenko and J. M. Gere, Theory of Elastic Stability, 2nd edition, McGraw-Hill, New York, (1961).

[13]W. J. M Steel and J. Spence, On the Propagating Buckle of Deepwater Pipelines. Proc of Offshore Mechanics and Arctic Engineering Conference ASME vol 5, Stavanger, Norway pp187192, (1983).

[14] S. Kyriakides, Buckle Propagation in Pipe-in-Pipe System, Part 1 - Experiment. Int J. of Solids and Structures, Vol 39, pp351-366, (2002).

[15]T. D. Park and S. Kyriakides, On the Performance of Integral Buckle Arrestor for Offshore Pipelines, Int Journal Mechanical Sciences, Vol39 No 6, pp 643-669, (1997). 